\title{
PERSPECTIVAS DE INVESTIGACIÓN EN TRADUCCIÓN EDITORIAL
}

\author{
Ana Luna Alonso
}

\begin{abstract}
After bearing in mind the need for carrying out more research projects focussed on an empirical basis so that training programs and teaching/learning activities have a practical and not an exclusively theoretical fundament, this paper proposes new analytical tools to understand translation for publishing companies within the context of minority languages and cultures. When the source or the target language is Galician, the translator and the several agents that intervene in carrying out such work and in its final result, need to perform a set of operations that belong to the mediation process. Even though a good number of specialists are interested in the what, when, where and how of things related to translation between major languages, our research is focussed on analysing the transfer process of minority languages and cultures.
\end{abstract}

Keywords: translation for publishing; minority languages and cultures; analytical tools; Galician.

Resumen: Teniendo en cuenta la necesidad de desarrollar más proyectos de investigación con base empírica para que los programas de formación y las actividades de enseñanza/aprendizaje tengan un fundamento práctico y no exclusivamente teórico; en este artículo proponemos nuevas herramientas de análisis para comprender el fenómeno de la traducción editorial en el contexto de una lengua y cultura minorizadas. Cuando la lengua de partida o de llegada es la gallega, la persona que traduce, así como los diferentes agentes que intervienen en el desarrollo del trabajo y en el resultado final, tienen que realizar una serie de operaciones propias del proceso de mediación. Mientras un buen número de especialistas se interesan por los problemas derivados del qué, cuándo, dónde y cómo traducir entre lenguas mayoritarias, queremos ocuparnos aquí del análisis del proceso de transferencia en el que intervienen lenguas y culturas minoritarias.

Palabras claves: traducción editorial; lengua y cultura minoritarias; herramientas de análisis; gallego.

Teño pre min que no caso hipotético de que un libro tan pouco comercial coma iste fose traducido ao chinés, quizais tivesen problemas os lectores da República Popular Chinesa coa mestura de linguas e fedellación de palabras. [...] E isto último aclároio pra facilitarlle o traballo ó tradutor barra a do galego ó chinés. Que ó mellor resulta que son dúas persoas, por exemplo unha galega que o traduce ó francés e logo un chinés que o traduce do francés á súa lingua. Algo así. Ou algo.

Cid Cabido 2006: 19, 21

Romanica Olomucensia 25.2 (2013): 127-143 (ISSN 1803-4136) 


\section{Consideraciones previas}

La traducción es un acto de comunicación que pone en contacto dos culturas. La persona que traduce no solo necesita llegar a ser experta en sus respectivas lenguas de trabajo, sino también en las culturas de dichas lenguas. En el caso concreto de la traducción en la que intervienen lenguas minoritarias y minorizadas (periféricas o marginales), los parámetros de investigación deben considerar que, además de una herramienta necesaria para facilitar la comprensión, la traducción posee una función normalizadora sociolingüística y cultural, que surge, en muchos casos, de la necesidad de reivindicar la diferencia.

Toda traducción está condicionada por unas necesidades y circunstancias precisas, que debe tener en cuenta a un público receptor, un determinado contexto cultural y un objetivo (o estrategia) establecido de antemano. Los creadores de la denominada Escuela de la Manipulación ${ }^{1}$ han sido fundamentales a la hora de incluir elementos de análisis que permanecían fuera del ámbito de estudio de la traducción. Partiendo de la Teoría del Polisistema, evolucionaron hacia orientaciones ideológicas como el estudio de los factores institucionales ${ }^{2}$ (Bassnet, Lefevere 1998), las relaciones de poder con la producción cultural o el interés por la actuación de los medios de comunicación y la(s) política(s) que esconden. Nunca se traduce de forma aislada, en abstracto y sin subordinación, la traducción tiene lugar en un momento y hacia o desde una cultura concreta.

Los textos traducidos determinan en gran parte la idea que tenemos de la otra cultura y viceversa. La inclusión de la perspectiva histórica en los estudios de traducción permite describir las traducciones y las relaciones entre culturas, además de ofrecer información sobre las relaciones que surgen en determinado sistema cultural, así como el efecto producido por la incorporación de los textos y sus características. Los enfoques comunicativos y socioculturales que recuperan los aspectos contextuales en los que se produce la traducción, haciendo especial hincapié en los elementos culturales y en la recepción de la traducción son los que mejor recogen hasta ahora los intereses de unos estudios de traducción de espacio cultural minorizado, por sopesar determinados aspectos como la función del texto de llegada o la manipulación del proceso y del producto, en los que la ideología (y la propia condición de minorizada) afecta de manera particular al fenómeno de la traducción (adaptación, retraducción, etc.).

Por otra parte, el enfoque sociológico aplicado a los estudios de traducción considera las condiciones sociales en las se producen y circulan las traducciones. Tiene en cuenta el trasvase cultural, sin abandonar los factores económicos. En el caso que nos trae aquí, es imprescindible analizar la propia imagen del concepto de traducción y de las traducciones. Cuando Even-Zohar (1978) estudia las relaciones entre el sistema de las traducciones y el de la creación, realiza una distinción entre los modos de comportamiento de culturas estables, que tienden a relegar la literatura traducida a los márgenes; pero valora de modo diferente la incorporación de los textos traducidos en comunidades pequeñas e inestables, por su papel central o primario. Gentzler (1993) apunta que se trata de relaciones variables en función de las circunstancias que operan en el interior de cada sistema. Los colectivos bilingües tienen presente en su imaginario la existencia de otra(s) lengua(s) y cultura(s) dominantes(s). La transferencia en la que intervienen

\footnotetext{
1 Que tiene sus continuadores dentro del espacio español en especialistas como Gallego Roca (1994), Carbonell (1997; 1999), Rabadán (1991; 2000), Vidal Claramonte $(1998 ; 2005 ; 2010)$, etc.

2 Editores, medios de comunicación, instituciones académicas, partidos políticos, clases sociales, etc.
} 
lenguas y culturas en proceso de normalización y minorizadas es diferente a la que se produce entre otras lenguas y culturas fuertes, normalizadas y hegemónicas:

[...] podemos determinar algunhas das funcións que se asignan á traducción nun sistema literario menor: primeiro, unha función expansiva que reforza o débil repertorio de formas discursivas xa presentes no sistema; segundo, unha función diversificadora que dá lugar ó aumento de discursos novos e moi necesarios; terceiro, un esforzó para contribuír á consolidación dunha nova poética en conficto aberto coa actual. Pero debemos distinguir outras dúas función máis: unha relacionada coa disposición para validar determinadas formas que xa están presentes no sistema aínda que nunha posición vulnerable; e outra responsable de asegura-lo status canónico dalgunhas formas discursivas (González Millán 1994: 68).

No es lo mismo traducir un texto canónico desde una lengua fuerte a una lengua fuerte que hacerlo hacia una lengua débil, como tampoco tiene el mismo poder canonizador traducir un texto procedente de un sistema marginal hacia un sistema consolidado que hacerlo hacia un sistema inestable y necesitado de reconocimiento social. En definitiva, no nos relacionamos del mismo modo con todas las culturas. En este sentido, el campo de estudio en el que nos situamos no es ajeno al concepto sociológico de «capital lingüístico» de Bourdieu (1992) sobre los beneficios asociados a la posesión de una lengua en el mercado lingüístico.

Existen situaciones en las que la mediación desde o hacia lenguas minorizadas se produce por necesidades básicas de comunicación y de supervivencia. En otros casos, como es el de la lengua gallega, además de las citadas, las necesidades de mediación vienen dadas porque el plurilingüismo oficial dentro de un Estado no implica el bilingüismo de sus habitantes. Hay que tener en consideración el derecho de los miembros de un grupo lingüístico asentado en un territorio bilingüe o plurilingüe a comunicarse en otra lengua distinta de la oficial, aunque se tenga competencia para hacerlo. Se trata de un acto de reivindicación identitario, como mecanismo que permite asegurar los derechos de los hablantes en su lengua propia, minorizada durante siglos ${ }^{3}$. Las comunidades que comparten dos lenguas se relacionan de modo muy diferente entre ellas con respecto a las lenguas más centrales y otras lenguas más periféricas. Existe toda una escala de valores y una casuística muy variada que prueba que las relaciones de poder siempre están presentes en los procesos de comunicación y la traducción no es ajena a esta eventualidad.

Sólo recientemente se ha abandonado en los Translation Studies la condición europea humanística y universalista, que no había permitido considerar la cuestión del colonialismo y de la hegemonía cultural, y en su lugar se propone un enfoque de relaciones lingüísticas y culturales bajo el prisma del poder, del dominio y de la desigualdad (Fouces González 2011: 46).

La comunidad gallega tiene especificidades en este sentido porque la ciudadanía es en su mayoría bilingüe (español-gallego) y, salvo situaciones muy concretas, no precisa de la traducción para acceder a los textos en español. Con todo, es una realidad que existe una fuerte demanda de traducción desde y hacia esta lengua, que ha atravesado diferentes fases a lo largo de los últimos años.

El Estatuto de Autonomía de Galicia de 1981 reconoce la cooficialidad que el gallego, como lengua propia de Galicia, comparte con el castellano, la lengua oficial del Estado español y cuyo fundamento jurídico también se establece en 1983 a través de la LNL que entre otros aspectos regula el uso del gallego en diversos ámbitos e incluye disposiciones con el fin de promocionar y oficializar la lengua gallega en los ámbitos administrativo, educativo y en

Galicia dispone de un importante legado literario cuyos inicios se suelen marcar a finales del siglo XII. 
los medios de comunicación. En los años ochenta del siglo pasado esta situación acarreó una repentina y elevada demanda de textos editados en la lengua vernácula, inicialmente centrado en material escolar y literatura dirigidos a un público infantil y juvenil (LIJ), que el sector editorial supo satisfacer en parte con traducciones sobre todo de textos españoles o a partir de traducciones españolas de textos redactados en una lengua extranjera (Montero Küpper 2012: 55).

En la actualidad, el volumen de traducción desde el español y para el español es la evidencia de, cuando menos, dos circunstancias: el gallego depende del español (y también del inglés) como lengua de origen de muchas traducciones para emanciparse de la lengua fuerte, y a su vez precisa de ella (por razones que van más allá de las estrictas necesidades de comunicación), para utilizarla como puente que le permita traspasar fronteras ${ }^{4}$. Este fenómeno también se produce a respecto del inglés, pero los comportamientos son diferentes y precisan de distinto análisis. En los últimos años, también hemos asistido a la experiencia de traducción directa desde y hacia el gallego sin necesidad de pasar por la mediación del español o del inglés, y este suceso se produce, tanto con culturas y lenguas hegemónicas (más o menos distantes), como con culturas y lenguas débiles; pero es imprescindible saber cómo y cuáles han sido las motivaciones de traducción en cada caso. La autotraducción al español es un modo de resolver la contradicción personal entre permanecer invisible o ceder ante una lengua que no se siente como propia. El traslado permitirá acercarse al gran público, sin dejar de reivindicarse ni modificar el discurso original, y conservará la existencia artística de autor y obra en otros espacios ${ }^{5}$. Cuando se traduce una obra gallega hacia el inglés, el proceso pasa por manos de una segunda persona, y mucha de la responsabilidad de que esa obra mantenga los elementos diferenciadores en la cultura importada está en la persona que traduce; aunque el éxito que consiga el texto en los diferentes espacios anglófonos dependerá del espacio público (editorial) que le haya sido reservado.

En los apartados que siguen, nos vamos a centrar en la producción de las traducciones editadas en lengua gallega en los últimos treinta años con el fin de ofrecer perspectivas de análisis sobre los flujos de traducción. A la hora de realizar un estudio sobre los textos traducidos publicados (normalmente en soporte libro), además del volumen producido, es imprescindible tener en cuenta el perfil del iniciador (normalmente la editorial) $\mathrm{y}$ de los agentes que intervienen en poner en marcha el proyecto, así como el proceso de elaboración del encargo dentro de la cadena industrial y el resultado como producto (demanda y recepción). Esta es la razón por la cual nos situamos en el ámbito de la traducción editorial. El análisis del contexto editorial en el que nacen los textos traducidos permitirá establecer las condiciones en las que se ha concebido un texto. La traducción es una práctica social que depende de aspectos internos como la actuación de las personas que traducen, los compiladores y los críticos, pero también depende de elementos externos como quién pone en marcha el proyecto y a qué intereses económicos e ideológicos responden dichas iniciativas. Partiendo del modelo de una lengua minorizada que convive en el mismo espacio con una lengua mayoritaria, nuestra línea de investigación pretende ofrecer herramientas específicas que faciliten el conocimiento de la identidad

4 La fundación y la consolidación de las editoriales gallegas se produce a partir de la aprobación del Estatuto de Autonomía y la Lei de normalización lingüística (LNL) de los años ochenta.

5 Sobre las autotraducciones del escritor gallego Manuel Rivas véase el artículo de López Salceda, Moreiras Arias, Pérez Feijoo, Rouco Paz y Santalla Fernández (2013) 
de los agentes culturales (la ideología editorial) que poseen la capacidad de decidir qué textos se traducen y cuáles no.

\section{La traducción editorial}

En el espacio de la didáctica de la traducción escrita es común diferenciar por niveles de aprendizaje entre traducción general y especializada. Esa diferenciación, que tiene su rendimiento y aplicación en el mundo académico, es completamente arbitraria y abstracta en el espacio profesional (aunque a veces se vincula con la diferenciación socioprofesional de tipo económico). Todos los textos que se traducen pueden ser más o menos especializados, esto es, exigen un trabajo de documentación, terminología y estilo propios.

Las obras literarias tienen la particularidad de poder combinar cualquier tipo de texto: narrativos, descriptivos, conceptuales, argumentativos, instructivos. Pueden producirse cambios de campo, ya que los textos literarios son híbridos en cuanto a los temas que tratan y pueden incluso albergar lenguajes de especialidad; cambios de tono, que reflejan las diferentes relaciones entre personajes, o entre narrador, personajes y público; cambios de modo, como la alternancia (en los narrativos) entre la narración propiamente dicha y el diálogo, que presuponen un medio oral. Pueden aparecer diversos estilos, diferentes dialectos sociales, geográficos, temporales, idiolectos particulares, con valores canónicos (es decir, inmutables y acuñados en cuanto a la forma). Además, suelen estar anclados en la cultura de partida y presentar, por lo tanto, múltiples referencias culturales (Marco, Verdegal y Hurtado 1999: 167-168).

La traducción editorial designaría en traductología un campo de la actividad traductora en el cual los textos traducidos están destinados a ser publicados por editoriales (Dragovic-Drouet 2005: 153). Así, en la categoría de traducción editorial incluimos todas las traducciones solicitadas por agentes o editores, destinadas a ser publicadas, con independencia del tipo de texto e incluso de la modalidad de traducción de que se trate.

Como toda industria, el sector editorial fomenta una actividad económica, es decir, elabora un producto comercial con fines lucrativos ${ }^{6}$. Dentro de su actividad mercantil, el sector busca modificar hábitos sociales, educar, informar y transformar la sociedad. Como industria cultural representa un importante agente de control (cultural), tanto en el espacio público como en el privado. Las editoras, entre otros agentes culturales, determinan en sus catálogos cuál va a ser el repertorio cultural de una comunidad.

El proceso de traducción desarrollado dentro de una editorial (subcontratado de manera externa, como sistema más generalizado), debe considerar toda una serie de cuestiones propias de la profesión, como cuáles son las reglas o normas de estilo de cada casa (aunque también hay normas externas de tipo social y estético), el control de la calidad y cuáles son las condiciones laborales de traductores, revisores y correctores. Al incluir la traducción en el campo editorial, podemos observar el trabajo del traductor como parte integrante de la cadena del libro a través de la cual pasan todos los manuscritos antes de que alcance la calidad requerida para su publicación. La calidad, indicaba Mario Merino (2005: 25), depende de la persona escogida por el editor. Como cualquier actividad humana, se trata de una cuestión ligada a la ética, es decir, la calidad del trabajo es el resultado de una digna compensación económica de la tarea emprendida por todos los que de

\footnotetext{
Según Antonio Ma Ávila (2010: 19, 20), el mundo del libro representaba en la fecha de realización del trabajo el 1,3\% del PIB nacional español, prácticamente la mitad (un 43\%) de la aportación de los sectores culturales al PIB y el $1 \%$ del total de la exportación de mercancías españolas. Casi un $28 \%$ de los nuevos títulos publicados son traducciones.
} 
algún modo «manipulan» el texto. La precariedad en la contratación perjudica de modo evidente a los profesionales, pero también afecta a la calidad media de las traducciones.

Las condiciones laborales del traductor, así como la selección de los textos que se traducen, están absolutamente relacionadas con la política editorial puesta en marcha por el iniciador (que acostumbra a ser el editor). El Estado español ha regulado las relaciones laborales mediante la Ley de Propiedad Intelectual ${ }^{7}$ y se han negociado los modelos de contratos ${ }^{8}$. En lo que toca a la propiedad de las traducciones de obras (artículo II) y, lo que es más importante, solo por el hecho de realizarlas (la Ley no exige su inscripción en el Registro de la Propiedad Intelectual), los traductores tienen el derecho exclusivo a explotarlas 9 . Con todo, los sucesivos informes elaborados como La traducción editorial en España (2010) o el Libro blanco de la traducción editorial en España (2010), basándose en encuestas realizadas a profesionales que trabajan con la lengua española ${ }^{10}$, manifiestan que los traductores son un grupo caracterizado por padecer unas condiciones laborales de debilidad.

Aunque un profesional de la traducción puede desarrollar su trabajo desde y para cualquier espacio de la mundialización, la práctica real de la labor de una persona que traduce desde o para el gallego está condicionada de manera particular por el mercado sociolingüístico en el que se mueve y las grandes diferencias que se producen entre unos y otros espacios. Si comparamos la situación entre los resultados del primer estudio de 2003 y los del estudio de 2010, esta no parece haber mejorado exponencialmente:

Los procesos de concentración editorial en grandes grupos multinacionales, que imponen a toda costa su ley de máximo beneficio empresarial, son una de las causas más aducidas por los consultados como origen, entre otros males, de este estancamiento de los porcentajes estipulados por derechos de autor de las traducciones. [...] La información constituye un elemento clave en las relaciones entre traductores y editoriales; sin información los primeros quedan inermes frente a las segundas, sin posibilidad real de defender sus derechos. La desinformación por tanto se convierte en la mejor arma de las editoriales para vaciar de contenido el posible respeto formal a los restantes derechos (VV. AA. 2003: 32, 33).

La palabra adecuada sería reclamar, reclamar lo que la ley les concede y aquello a que los hace acreedores su categoría de indispensables «agentes sociales» de la política cultural de un país y de generadores, en la parte que les corresponde, del bienestar intelectual de sus conciudadanos; $y$, no menos, su condición no de «parásitos de la literatura» o de reivindicadores de un jactancioso "quiero y no puedo», como parece que hay quien los considera de forma más o menos implícita, sino de generadores de beneficios dignos de consideración para la industria editorial. Es decir, de creadores de riqueza en sus más amplios y varios sentidos (MCU 2010: 9).

\footnotetext{
7 Cf. Los capítulos primero y segundo del título V, en http://noticias.juridicas.com/base_datos/Admin/ rdleg1-1996.html (consulta 30-07-2013).

8 Tras la publicación del Libro Blanco (1997), la Federación de Gremios de Editores (FGEE), la Asociación Colegial de Escritores, la Sección Autónoma de traductores de libros de la ACE (ACEtt) y la Federación de Asociaciones de Ilustradores firmaron un acuerdo de uso de unos modelos de contratos de traducción (Madrid, 29 de julio de 1999). Véase http:/ / www.acett.org/ fijos.asp?art=15 (consulta 30-07-2013).

9 La aparición de las nuevas tecnologías condiciona el modo en que se deben establecer las relaciones contractuales entre editor y traductor ante el libro electrónico o la obra multimedia. Véase http:/ / www.ace-traductores.org/node/ 432 (consulta 30-07-2013).

${ }^{10}$ Han sido consultados socias y socios de ASETRAD, APTIC, EIZIE, AGPTI, ACEC y UNICO.
} 
Coincidimos con los representantes de los diferentes colectivos profesionales en que las administraciones deben hacer todo lo posible por dar a conocer la ley y velar por su garantía.

[...] la situación de la profesión de traductor en España, a partir del año 1996, no sólo no ha mejorado sino que se han acentuado en ella las contradicciones y los signos de preocupación que se desvelaban en el trabajo que sirvió de base para la confección del «Libro Blanco de la Traducción», en ese mismo año 1996. [...] La valoración negativa se expresa desde luego de forma mucho más acusada entre los traductores profesionales «en sentido estricto» que entre aquellos otros que «no viven» de la traducción. (VV. AA. 2003: 77, 78)

El texto del 2010 es poco alentador, según Ávila:

Y para terminar, quiero señalar algunos datos que me resultan curiosos o me dejan perplejo, por ejemplo, que aún haya un $27,2 \%$ de traducciones sin contratos anualmente. Más dudoso, y por tanto necesitado de aclaraciones, es lo que el estudio entiende por «prácticas abusivas» en los contratos (Ávila 2010: 20).

El informe de 2010 diferencia entre editores «fabricantes de libros» y editores «intelectuales». Los primeros ven el mundo editorial en general como un negocio lucrativo y piensan que la traducción es un gasto. Los segundos son conscientes de la importancia de su labor, del trabajo del traductor y de que la introducción de un autor en su catálogo es una decisión que puede provocar cambios importantes en la cultura receptora.

Son ya muy pocos los profesionales que editen lo que realmente quieren y no lo que el director ejecutivo del grupo-empresa editorial pretenda sacar a la venta como el «mejor libro del mes». Prueba de que el valor de lo literario ha descendido hasta niveles mercantiles insospechados es el epíteto del «libro más vendido», o bien «se lee con asombrosa facilidad» (Gómez García 2003).

Entre los cambios producidos en 2010, destacamos las prioridades de las editoriales que determinan el trabajo del traductor:

a. Prioridad a los libros más vendidos sobre los clásicos.

b. Prioridad de los consagrados modernos sobre los nuevos valores.

c. Prioridad de los nuevos géneros (autoayuda, facilitadores de los conocimientos, manuales)

(MCU 2010: 43).

Para que el editor (la persona física o jurídica que pone los medios materiales económicos para divulgar una obra) disponga de un mercado editorial competitivo, es preciso crear las condiciones necesarias que permitan el desarrollo de la traducción. En este sentido apuntaba Luis Magrinyà:

El inglés, que domina el mercado editorial, define lo que es «internacional» y lo que no, y a menudo lo hace a costa de fomentar su propia construcción de los estereotipos nacionales: un autor balcánico que escriba una novela, por ejemplo, no situada en los albores, el curso o las postrimerías de las guerras de los Balcanes tiene muchísimas menos (próximas a cero) probabilidades de ser traducido al inglés que uno que le dé al inglés lo que el inglés espera de él. A un escritor balcánico se le pide que haga «balcanismo», y éste es un peaje, en cualquiera de sus cotizaciones folklóricas, que parece que tienen que pagar la mayoría de los escritores que aspiren a formar parte del curioso mundo global. Es decir, del mundo que se habla y escribe en inglés (Magrinyà 2010: 30).

La literatura importada se debate en general entre el proyecto cultural que busca textos renovadores y el proyecto comercial (aunque en ocasiones pueden coincidir). En el caso de Galicia, podemos realizar un paralelismo semejante, pero de nuevo las condiciones 
socioeconómicas marcarán las prácticas traductoras, porque al tratarse de una comunidad bilingüe, el proyecto comercial también compite dentro de su marco territorial.

\section{Tipología editorial y bibliodiversidad}

Con el fin de observar la capacidad potencial y real de promover la traducción de los textos de un determinado editor, Fukari $(2005: 144,145)$ propone un modelo de análisis que parte del concepto de capital de Bourdieu (1999). Cada editorial ocupa una posición en el campo editorial, que depende de la distribución de los recursos (económicos, simbólicos, técnicos, etc.) y de los poderes que tienen sobre el propio campo. Esta posición orienta las decisiones de sus responsables y sus estrategias de selección a la hora de publicar tanto creación como traducción.

Le plus gros des changements observés dans la politique éditoriale des différentes maisons peut ainsi être rapporté à des changements de la position qu'elles occupent dans le champ, le déplacement vers les positions dominantes s'accompagnant d'un renforcement de la tendance à privilégier la gestion des acquis au détriment de la recherche de la novation et à mettre le capital symbolique détenu au service d'auteurs beaucoup plus « commerciaux » que ne l'étaient, aux temps héroïques des commencements, ceux qui ont contribué à l'accumulation de ce capital (Bourdieu 1999: 4).

Es decir, se trata de la hipótesis según la cual el poder de los editores depende del volumen de capital del que dispongan: de su capital económico, cultural, social y simbólico. Para medir el volumen de cada capital en cada caso, es imprescindible aplicar diferentes parámetros. Así, para medir el capital económico, hay que conocer el volumen de facturación de la editorial, su nivel de independencia respecto de un grupo, la cantidad de subvenciones que recibe, el número de empleados dentro de su plantilla y la existencia (o ausencia) de un servicio de gestión de derechos extranjeros. Para determinar el capital cultural hay que tener en cuenta el número de títulos (originales y traducciones) del catálogo del editor y el capital cultural institucionalizado del mismo y el de sus empleados. Para conocer el capital social, es necesario analizar la extensión y el peso de la red social profesional con la que está en contacto el editor (otras editoriales, agencias literarias, traductores, críticos, medios de comunicación, instituciones públicas o privadas...). Por último, para evaluar el capital simbólico es imprescindible establecer cuál es el lugar que ocupan el editor, sus autores y sus textos en el campo literario nacional e internacional (premios, «categorías» de lenguas, etc.).

La voluntad del editor del texto original no es suficiente para poner en marcha el motor de la traducción, ésta depende a su vez del capital que pueda atraer, es decir, del capital económico, social, cultural y simbólico que pueda acumular. Con todo, en la actualidad es difícil sobrevivir a un mercado globalizado y guiado por intereses políticos que concentran el poder económico:

A través del poder casi absoluto que ejercen sobre los grandes grupos de comunicación, es decir sobre el conjunto de los instrumentos de producción y de distribución de bienes culturales, los nuevos amos del mundo tienden a concentrar todos los poderes, económicos, culturales y simbólicos que, en la mayoría de sociedades, se habían mantenido diferenciados, incluso enfrentados, y de esta forma están en condiciones de imponer ampliamente una visión del mundo acorde con sus intereses (Bourdieu 2001: 96, 97).

Los editores le conceden de manera general una especial atención al equilibrio entre los fondos y las novedades. Una editorial fuerte puede invertir tanto en literatura propia 
de creación como extranjera, en ficción, ensayo o en otras disciplinas. Sin embargo, la literatura extranjera (entendida como todo lo que se importa y no solo la ficción), puede ser un medio de acumulación de capital simbólico para una editora joven o pequeña (en general independiente), que carezca de años de experiencia o de reconocimiento social. Constituir un catálogo de autoría extranjera parece ser más fácil que crear un catálogo de creación propia, porque en ocasiones es difícil fidelizar a una determinada autora o autor de ámbito nacional. El coste de la literatura extranjera puede aportar beneficios inesperados, dado que antes de llegar a las manos de la editora se entiende que las obras ya pasaron por un filtro previo en el país de origen, así como por el circuito de transferencia que presupone cualquier traducción: editores extranjeros que poseen los derechos, agentes y agencias literarias, público lector, etc. Para proceder a seleccionar una obra exportable de su catálogo, el editor se basa en criterios centrados en la experiencia que le permite estimar los libros susceptibles de conocer una buena acogida en el exterior. Para el editor que cede los derechos, los gastos que implican este tipo de operaciones suponen cierta intuición, así como un determinado conocimiento de los mercados foráneos y características que definen las líneas editoriales con las que tienen o establecen diferentes relaciones.

La competencia entre editores (tanto vendedores como compradores de derechos) o los efectos de las circunstancias políticas (que pesan en el interés de editores y público por determinada literatura extranjera) dificultan la formalización de lo que se selecciona e implica la movilización de múltiples recursos por parte de los agentes del mercado (Luna Alonso 2011). Una colección extranjera puede ser un buen mecanismo para imponerse como editorial y acabar atrayendo a autores propios. Por otra parte, la predisposición para «vender» a los propios autores también es un valor añadido nada despreciable. Es preciso observar que para los autores de la casa, la traducción en una lengua extranjera es una demostración de dedicación por parte de la editorial. Un reconocimiento de su interés.

En las comunidades con lenguas minoritarias, la falta de un departamento de gestión externo lleva a las editoriales a dejarse orientar por los representantes de la academia o por las propias personas que traducen, a la hora de decidir qué se publica. Estos agentes colaboran con el editor, concediéndole un plus de prestigio y autoridad a la obra traducida, en el caso de profesores o autores de reconocimiento interno. Con todo, hay que ser cauteloso con el repertorio seleccionado que acabará por definir qué es lo mejor de la producción de cada comunidad. Los paratextos que acompañan a las traducciones se revelan de especial utilidad en el caso de lenguas minoritarias, porque los conocimientos del público sobre la obra importada acostumbran a ser menores que los del público en general ${ }^{11}$.

\section{Perspectivas de investigación}

En las líneas que siguen, avanzamos en ofrecer propuestas de investigación que consideramos aplicables al fenómeno de la traducción editorial en el contexto de una lengua y cultura minorizadas desde un enfoque multidisciplinar y lo suficientemente amplio para acoger a todos y cada uno de los componentes que intervienen en el proceso y en el resultado traductológico. Nos interesamos en particular por presentar la situación de los

$\overline{11}$ Véase, en la bibliografía, el artículo sobre texto y paratexto de Garrido Vilariño (2005). 
problemas derivados del qué, cuándo, dónde y cómo traducir entre culturas minoritarias partiendo del ejemplo concreto de la cultura gallega. Para ello, hemos dedicado nuestro trabajo a reunir datos fiables y hemos procedido a obtener las herramientas de análisis que nos permitirán considerar desde una perspectiva científica el modo de relacionarse de todos los elementos implicados.

Treinta años después de la aprobación de la Lei de normalización lingüística, nos podemos aventurar a hacer algún pronóstico sobre tendencias, así como propuestas de análisis para el futuro, desde el punto de vista de los estudios de traducción de ámbito gallego. El campo de la traducción editorial permite descubrir las debilidades y fortalezas en un espacio que va más allá del fenómeno literario y facilita una panorámica mucho más amplia de las políticas de edición seguidas en este período.

La producción de traducción en lengua gallega en formato libro se ha desarrollado de modo exponencial a lo largo de las últimas décadas. La normalización del gallego como lengua de enseñanza y su progresiva presencia en los medios de comunicación ${ }^{12}$ favorecieron el aumento de la demanda de libros y la activación del mercado editorial. A pesar de lo positivo de las cifras, salvo las colecciones de clásicos de literatura infantil y narrativa dirigida al público adulto, es necesario indicar que la planificación de importación y exportación de textos, tanto por parte del sector público como del privado, resultó ser algo caótica, en la que no parecía haber un criterio común sino intereses particulares. Una circunstancia que no debe ser ignorada, puesto que, tal y como indicaba Even-Zohar (1978), la planificación cultural proporciona cohesión sociocultural y puede llegar a convertirse en una condición necesaria para la creación o incluso para la supervivencia de las entidades sociales.

Según los datos del estudio titulado Comercio Interior do Libro en Galicia 2011, elaborado por los responsables de cultura del Gobierno de la Comunidad Autónoma de Galicia $^{13}$, en el año 2011 computamos un total de 48 empresas editoriales agremiadas en la Asociación Galega de Editores (AGE). De entre ellas, un 52,2\% (25) forma parte de un grupo empresarial y el 47,8\% restante (23) son independientes. El 86\% de los libros editados salieron de editoriales privadas, un 70\% asociadas a AGE. Tanto los libros de creación como las traducciones editadas en gallego se concentran en tres materias: texto no universitario $(33,8 \%)$, infantil y juvenil $(26,4 \%)$ y literatura $(23,9 \%)$. Entre ellas suman el $84,1 \%$ del total ${ }^{14}$. El número de empresas que editaron en 2011 en Galicia se distribuye como sigue:

112 editoriales privadas con sede en Galicia (48 en la AGE y 64 no agremiadas).

31 autores editores o editoriales de pequeño tamaño.

26 entidades públicas con servicio editorial.

En la actualidad contamos con editoras que disponen de un catálogo en el que la literatura traducida importada ocupa un papel relevante dentro de su producción e incluso ofrece colecciones en las que el porcentaje de traducción tiene cierto peso. Existe un pequeño número de editoras que traducen y editan fundamentalmente material educativo

\footnotetext{
12 Para conocer cuál ha sido el papel de la televisión autonómica, recomendamos el volumen de Montero Domínguez (2010).

${ }^{13}$ En http://cultura.xunta.es/imxd/noticias/doc/informeedicion2011.pdf (consulta 30-07-2013).

14 Según la Panorámica de la edición española de libros (2011), en Galicia se inscribieron 3.384 ISBN. El 13,9\% fue editado por las administraciones públicas, mientras que el restante $86,1 \%$ ( 2.734 títulos) se debe a edición de carácter privado, aunque 286 títulos corresponden a autores editores.
} 
y literatura infantil de modo casi simultáneo en las cuatro lenguas oficiales del Estado (aunque no todas tienen sede social en Galicia). También están las empresas centradas en la edición de textos técnicos, manuales universitarios y proyectos enciclopédicos (traducidos en su mayoría del español). Un reducido grupo publica ensayo importado, textos de divulgación científica, etc. Por último, es importante destacar la existencia de jóvenes editoras especializadas en traducción de narrativa para adultos que procuran un espacio en el mercado de la exportación directa de autores y autoras gallegos hacia el español.

Entre las editoras locales que más traducen, debemos destacar el papel continuador de Edicións do Castro o el de la Editorial Galaxia, durante la dictadura franquista. Galaxia ha incorporado importantes colecciones en los últimos años de la democracia como: la «Biblioteca Compostela de Narrativa Europea» (colección que ofrece varias obras en gallego antes de que aparezcan en otra lengua europea), la «Literaria», los «Clásicos Universais», los «Clásicos en Galego» y las dirigidas al público más joven como «Costa Oeste» $\mathrm{y}$ «Árbore», en las que también se incluyen numerosas traducciones. La otra editora fuerte del mundo editorial gallego, que siempre ha tenido muy presente la traducción, es el proyecto de Edicións Xerais de Galicia. Xerais, además de la colección específica dedicada a los "Clásicos Universais», incluiría obras foráneas en las colecciones de más éxito como son «Narrativa», «As Literatas», «Fóra de Xogo», «Xabaril» o «Xabarín de Ouro» para los más pequeños.

A lo largo de los últimos años, se ha ido consolidando el trabajo de empresas como Laiovento, Sotelo Blanco, Baía, Ir Indo, Tris Tram, Toxosoutos, Positivas o Espiral Maior; y han nacido otras como la premiada Kalandraka, OQO, Faktoría K, Rinoceronte, Barbantesa, Urco, 2.0 Editora, Morgante, Hugin \& Munin, Ézaro Ediciones, Triqueta Verde o Franouren. Dentro de este panorama autonómico, no podemos olvidar la competencia comercial ejercida por las casas de ámbito estatal e incluso supraestatal con sello propio como Rodeira Galicia (Grupo Edebé), Tambre (Grupo Luis Vives), Tàndem, Bruño-Salvat, Everest Galicia, Planeta-Oxford, Xerme Editora (SM), Obradoiro (Grupo Santillana) o la catalana El Aleph. Estas últimas se encontrarían en el campo de la gran producción, frente a las empresas locales, que aunque disponen de un capital económico muy desigual, también disfrutan de un capital cultural, social y simbólico a diferente escala. De hecho, las editoriales destinadas al mundo académico son diferentes de las que tienen por objeto textos que puedan alcanzar un gran número de lectores. Como ya indicamos más arriba, el sector privado editorial se ha visto obligado a abandonar la política tradicional del libro de cultura para poder sobrevivir en un mercado que exige cada vez más beneficios. Habrá que ver qué capacidad de resistencia mantienen las pequeñas editoras que, dentro del panorama gallego, son la práctica mayoría, y además, suelen publicar solo en lengua gallega.

Para proceder a cualquier investigación sobre el perfil del sector, es necesario disponer de un registro exhaustivo y fiable que recoja los datos sobre la traducción en lengua gallega ${ }^{15}$. Los datos nos ofrecen información sobre qué traducimos y nos permiten hacernos las preguntas lógicas sobre cuáles han sido las políticas de traducción públicas

\footnotetext{
${ }^{15}$ El Ministerio de Ciencia y Tecnología primero, y el Vicerrectorado de investigación más tarde, le han concedido al grupo de investigación BITRAGA de la Universidade de Vigo, del que soy responsable, diferentes ayudas para llevar adelante la catalogación de las traducciones literarias en formato libro realizadas en gallego desde 1980 (BFF2003-02505). La base de datos es de acceso público en http:/ / www.bibliotraducion.uvigo.es/ (consulta 30-07-2013) y pretende compilar todo tipo de textos y formatos.
} 
y privadas de la producción editorial. Es imprescindible conocer el mercado editorial propio y ajeno, porque debemos saber con quién nos relacionamos y quién se relaciona con nosotros y cómo. Es decir, qué textos (literatura o no) importamos y qué textos no importamos, qué culturas, qué géneros (narrativa, poesía, teatro y ensayo, etc.), qué autores (contemporáneos, clásicos contemporáneos o clásicos), quién traduce, quién publica y cómo atraviesan fronteras y mercados.

En el ámbito cultural gallego, la traducción literaria implica prestigio, sobre todo cuando se trata de importar textos clásicos o contemporáneos de éxito o premiados; pero la traducción de libro de texto o la del denominado producto paraeducativo representan el volumen más significativo de facturación en traducción editorial. Producimos libros que en su mayoría identificamos con literatura (mucha más narrativa que poesía o teatro), mas tenemos muchas dificultades para atraer otros tipos y modalidades de textos, incluso de creación en lengua propia, porque carecemos de suficiente mercado y, por lo tanto, de editoriales y agentes que provean el campo editorial de textos demandados para la normalización cultural.

Si durante años la importación y sobre todo la exportación editorial fueron actividades minoritarias, en la actualidad, y visto el volumen de obras traducidas, podemos afirmar que la producción ha alcanzado cifras homologables a otras literaturas de sus características. A finales del siglo pasado se produjeron resultados muy positivos en lo que respecta a la traducción, que se consideró estratégica en la producción editorial.

Sin renunciar a la publicación de los clásicos (que se han podido interpretar desde una lectura contemporánea, como apuntaba Lefevere (1992: 69,70), poniendo al día el original), se han producido apuestas que se desvían de prácticas de planificación ortodoxas, al importar determinadas obras contemporáneas con temática reivindicativa, que describen, por ejemplo, la situación de la mujer; sin embargo, proyectos de estas características no deberían ser productos discriminados y relegados a colecciones particulares que procuran la compensación genérica en los catálogos.

La especialización editorial parece ofrecer buenos resultados, dado que han surgido pequeñas empresas independientes que han establecido acuerdos para importar textos de calidad hasta ahora desconocidos, incluso en comunidades que movilizan un importante capital económico. En esa misma línea debemos incluir producciones que dan a conocer textos alternativos a los que mueven los mercados globalizados. La preocupación por disponer del canon occidental en gallego puede llevar consigo la reproducción de esfuerzos inútiles. Es preciso analizar qué utilidad tiene traducir determinadas obras consideradas «fundamentales», si la única razón de su importación es la simple imposición de las culturas dominantes. Debemos valorar qué puede ser más rentable y establecer un diálogo con las obras procedentes de sociedades con menos oportunidades de ser conocidas, aprovechando los recursos. Con todo, dicha empatía no debe pasar por inercias asumidas como la de la identificación cultural, sino como estrategia para mostrar lo que realmente importa.

Para conseguir ser autónomos, es necesario importar menos textos procedentes del español o desde el inglés, y ampliar el espectro de lenguas y territorios menos traducidos. No podemos obviar que el libro en gallego se produce bajo el dominio de fuertes grupos editoriales (absorbidos, a su vez, por grandes multinacionales que también son dueñas de los medios de comunicación). El ritmo de la producción en gallego no puede competir con la del español, y si lo pretende, el fenómeno se puede volver en contra 
de sus propios intereses, porque las traducciones pierden o carecen inicialmente de su función principal (la de acercar nuevos mundos y formas de expresión), para pasar a ser elementos, ya no simbólicos, sino en ocasiones folclóricos, que se convertirían en objetos propios de museos. Por otra parte, la traducción para el español puede ser (y acostumbra a serlo) un primer paso para salir fuera del espacio ibérico. Con todo, no es la primera vez que la literatura gallega se vende fuera del Estado, como si de literatura española se tratase, porque no hay nada en los créditos que indique que el texto es de autoría gallega y ha sido escrito originalmente en gallego ${ }^{16}$. Si tenemos en cuenta las relaciones de poder que se establecen en el mercado de la traducción, es muy probable que una de las razones que lleve a que no se indique el dato del original es que la editora considera que la autoría y la obra venderán más, o tendrán mejor acogida, si su presentación en sociedad es la de tratarse de un original castellano. Tal y como apunta Fouces González (2011: 22), aunque la autora se refiere a la literatura sueca traducida al italiano, este sería un ejemplo de lo que se ha dado en llamar texto globalizado «en los que se ha cancelado toda huella de la cultura nacional en la que fueron producidos y aspiran a ser 〈literatura del mundo»».

Otro polo de interés en un estudio sistemático sobre la traducción en el ámbito editorial es el análisis de los agentes que intervienen en el proceso mediador y cómo funcionan los circuitos de exportación e importación (productores, consumidores, productos, mercado, instituciones y repertorio). Es preciso analizar qué textos importamos de cada uno de los diferentes espacios lingüísticos y culturales como el anglófono (y si el inglés es lengua puente y por qué), así como valorar cómo son nuestras relaciones con las otras lenguas del Estado español (el caso del catalán y el de la literatura infantil y juvenil traducida es especialmente significativo). La selección de los textos corresponde en general a criterios comerciales que dependen de los acuerdos entre editoriales, o a decisiones de los grandes grupos ${ }^{17}$ competitivos en la escala internacional o a factores como los derechos de autor y de traducción. Con todo, sigue siendo mucho más frecuente la importación que la exportación de obras literarias y, en este mismo sentido, es común que aparezcan obras de la literatura clásica (o clásica contemporánea en los últimos años) considerada universal, traducidas al gallego que no están traducidas en español, un hecho que cuando menos «enrarece» el sistema. Es necesario analizar cuáles son los espacios de importación y de exportación más olvidados y por qué.

Además de los agentes iniciadores del proceso de la traducción, la crítica interna y foránea tiene un papel fundamental respecto de la configuración del canon de la traducción. Tal y como indica Casanova (2002: 17), la traducción literaria es un mecanismo de transmisión de capital literario, el valor de la traducción y su grado de legitimidad dependen del capital lingüístico-literario de la lengua de llegada (a los que hay que añadir el del editor, el de la colección o de la revista en la que aparece el texto, etc.). Si partimos de la posición que ocupa el mediador en su campo nacional, de la posición de la lengua de llegada y de la posición del editor del libro traducido, podemos deducir el grado de

\footnotetext{
${ }_{16}$ En muchas ocasiones, las razones están en la apropiación de las diferentes lenguas y culturas del Estado por parte de la cultura española, más que por encubrir la ilegitimidad de hacer llegar una traducción gallega a otra lengua de manera indirecta a través del castellano.

17 Los grandes grupos como Planeta, Everest, Santillana y SM, que hasta hace poco carecían de sede y de sello editorial en Galicia, ocupan un amplio espectro del mercado del libro educativo y de la literatura infantil y juvenil en las lenguas del Estado y compiten con las pequeñas editoras locales en sus respectivos espacios autonómicos.
} 
legitimidad del texto. Nos interesa pues saber en qué medida modifica el repertorio de creación la importación de los textos.

Chaque œuvre venue d'un espace nationale peu doté, qui prétend au titre de littérature, n'existe qu'en relation avec les réseaux et la puissance consacrante des lieux les plus autonomes. [...] C'est pourquoi, dans l'univers littéraire mondial, la traduction est à la fois l'une des armes principales dans la lutte pour la légitimité littéraire et la grande instance de consécration spécifique (Casanova 2002: 13-14).

Todavía existe el concepto heredado del escritor-traductor gallego de mediados del siglo $\mathrm{XX}$, que concebía la traducción como una herramienta de enriquecimiento lingüístico y de prestigio literario. De hecho, la valoración de los textos traducidos (y la calidad de la traducción en sí misma) por parte de la crítica literaria se centra, aún en la actualidad, en la función simbólica de la traducción y en la opción domesticadora del mediador (Luna 2010). Las instituciones literarias de prestigio (jurados de premios, academias, etc.), tienen la capacidad de determinar el valor simbólico de la consagración artística y de convertir en obras de interés determinados productos. La opinión general es que lo fluido y escrito con corrección según la norma de la lengua de llegada es lo bueno y el componente de extrañamiento debe quedar fuera como negativo para la propia cultura que lo acoge. Si bien esto parece que está cambiando de manera tímida en los últimos tiempos, y se ha dotado a la traducción y a las personas que traducen de cierta confianza por parte del público lector; el abandono de otros espacios y voces actuales o la recurrencia sistemática a la traducción de obras clásicas (traducidas por autoridades, liberadas de las contingencias del mercado y con funciones diferentes a las originales); resulta ser un indicador más de que el sistema tiene dificultades para desprenderse de la idea de que la traducción es una actividad secundaria.

\section{A modo de conclusión}

Los criterios de selección de las obras traducidas vienen determinados por la situación en el sistema local, que puede encontrarse en fase de formación y al mismo tiempo ser frágil (aunque hay niveles de fragilidad), es decir, dependiente de lo que se hace en culturas consideradas estables. Del mismo modo, las estrategias adoptadas para traducir un texto pueden encontrarse en la línea del distanciamiento de lo que se considera dominante, establecido y prescrito. Se escoge en función de la compatibilidad con las nuevas tendencias y con su función innovadora dentro de la cultura receptora, pero lo que parece novedoso puede ser simplemente la constatación de otra dependencia. Así, que una editorial gallega importe textos procedentes de espacios inéditos para el público lector gallego no quiere decir que esta literatura no forme parte de un canon en su espacio de origen. Solo en el caso de que se importe algo nuevo en el sistema de origen, puede representar una novedad real en el sistema de llegada. Incluso dentro de la Europa que legitima la valía de los textos hay escalas de valores.

Las razones de que nuestro sistema se mantenga en una línea proteccionista (en materia de importación y exportación) hay que atribuirlas, en parte, a la propia debilidad del sistema y, en parte, al escaso apoyo ofrecido por las instituciones responsables en dinamizar el sector del libro en lengua propia. Estas carencias, unidas a las dificultades económicas con las que se encuentran las editoras privadas para poder publicar obras contemporáneas importadas, tienen como consecuencia que nos encontremos con un panorama en el cual todavía no se ha dado el salto cualitativo ni cuantitativo, desde que 
los principales agentes mediadores de principios del siglo pasado decidiesen traducir de modo altruista las obras que consideraban de interés para prestigiar la lengua. Gracias al compromiso institucional en períodos muy breves de la historia reciente, y de las editoras locales que arriesgan y apuestan por la traducción contemporánea, así como al éxito en el exterior de algunas obras de autoría gallega, los catálogos se han ido diversificando en lenguas y espacios de origen, hasta el punto de competir por un mismo público el sector editorial gallego y el español. La actual crisis económica ha tenido consecuencias graves para el sector cultural en general, y las más inmediatas se han dejado sentir en el descenso de la producción, así como en la tendencia al conservadurismo a la hora de publicar determinadas autorías y obras.

Cuando una lengua periférica se traduce a una central, la transferencia genera legitimidad y el texto adquiere prestigio interno y externo. Así, también es preciso analizar el papel de las instituciones públicas y privadas en el desarrollo y promoción del sistema editorial de la traducción. Uno de los cometidos de la investigación es conocer cuáles son los intereses que desencadenan la concesión de las ayudas institucionales y cómo se organizan las relaciones entre el sector editorial privado y las diferentes administraciones, cuáles son los programas de ayuda dirigidos a los profesionales de la traducción o cuál es la inversión necesaria en formación superior. En definitiva, debemos ocuparnos de la promoción interna (los premios, difusión en los medios de comunicación...) y externa (las ferias, los centros de estudios gallegos en el exterior, los encuentros internacionales de investigadores...), así como de cuáles de estas medidas han obtenido mejores resultados y por qué. Quizás fuese útil que la academia, las administraciones y la iniciativa privada se pusiesen de acuerdo junto con los colectivos sociales vinculados de una manera u otra con la traducción, para definir y elaborar la política de traducción que mejor se ajuste a las características y necesidades de una comunidad como la que queremos estudiar.

\section{Bibliografía}

Ávila, Antonio Ma (2010), «El Libro Blanco de la traducción editorial en España. Su importancia», in: MCU, Libro Blanco de la traducción editorial en España, Madrid: MCU, 19-20.

BASSNETt, Susan - LefeVere, André (1998), Constructing cultures: essays on literary translation, Clevedon: Multilingual Matters.

Bourdieu, Pierre (1992), Les règles de l'art. Genèse et structure du champ littéraire, Paris: Éditions du Seuil.

Bourdieu, Pierre (1999), «Une révolution conservatrice de l'édition», Actes de la recherche en sciences sociales 126-127, 3-28.

Bourdieu, Pierre (2001), Contrafuegos 2, Por un movimiento social europeo, Barcelona: Anagrama [Traducción española de Joaquín Jordá. Original de 2001: Contre-feux 2. Pour un mouvement social européen, Paris: Éditions Raison d'agir].

Carbonell i Cortés, Ovidi (1997), Traducción, Exotismo, Poscolonialismo, Cuenca: Universidad de Castilla-La Mancha.

CARbonell Cortés, Ovidi (1999), Traducción y cultura: de la ideología al texto, Salamanca: Colegio de España.

Casanova, Pascale (2002) «Consécration et accumulation de capital littéraire. La traduction comme échange inégal», Actes de la recherche en sciences sociales 144, 7-20. 
Cid Cabido, Xosé (2006), Blúmsdei, Vigo: Xerais.

Dragovic-Drouet, Mila (2005), «L'apport de la notion de traduction éditoriale à une typologie de l'activité traduisante», in: PeETERs, Jean (ed.), La traduction. De la théorie à la pratique et retour, Paris: PUR, 151-158.

Even-Zohar, Itamar (1978), «The Position of Translated Literature Within the Literary Polysystem», Poetics Today XI, 1 [Traducción española de Monserrat Iglesias Santos (ed.) (1999), in: Teoría de los Polisistemas, Madrid: Arco/Libros, «La posición de la literatura traducida en el polisistema literario», 223-231].

Fouces GonzÁLEz, Covadonga (2011), La traducción literaria y la globalización de los mercados culturales, Granada: Editorial Comares.

FUKARI, Alexandra (2005), «Les maisons d'édition - Freins ou moteurs du processus de traduction ?», in: PEETERS, Jean (ed.), La traduction. De la théorie à la pratique et retour, Paris: PUR, 141-150.

Gallego Roca, Miguel (1994), Traducción y literatura: los estudios literarios ante las obras traducidas, Madrid: Jucar.

Garrido Vilariño, Xoán Manuel (2005), «Texto e paratexto. Tradución e paratradución», Viceversa, Revista Galega de Tradución 9/10, 31-39.

GentZleR, Edwin (1993), Contemporary Translation Theories, Frankfurt: Lodge.

Gómez García, Carmen (2003), «El traductor literario: ¿traidor o traicionado? (la traducción de textos literarios de lengua alemana en España)», Enlaces 0 (http:/ / www.cesfelipesegundo.com/revista/Articulos2003/Articulo11.htm, consulta 1007-13).

GonZÁlez Millán, Xoán (1994), "Cara a unha teoría da tradución para sistemas literarios «marxinais». A situación galega», Viceversa. Revista Galega de Tradución $1,63-72$.

LEFEVERE, André (1992), Translation, Rewriting and the Manipulation of Literary Frame, London-New York: Routledge.

Lefevere, André - Lambert, José (1993), La Traduction dans le développement des littératures, Louvain: University Press.

LóPEZ SALCEDA, Sandra et alii (2013) «Análise de tradución/autotradución: Muller no baño (Manuel Rivas)», Romanica Olomucensia 25.1, 21-35.

Ley de Propiedad Intelectual. Real Decreto Legislativo 1/1996, de 12 de abril (http:/ / www.acett.org/, consulta 10-07-13).

Luna Alonso, Ana (2010), «A crítica da literatura traducida nas páxinas culturais da prensa», in: BALSTRUG, Burgard et alii (eds.) Soldando sal. Galician Studies in Translation \& Paratranslation, München: Martin Meidenbauer, 107-130.

Luna Alonso, Ana (2011) «Analysis Criteria for Editorial Translation Policies», in: Luna Alonso, Ana - Montero Küpper, Silvia - Valado Fernández, Liliana (eds.), Translation Quality Assessment Policies from Galicia, Frankfurt am Main: Peter Lang, 217-234.

MAGRINYÀ, Luis (2010), «El valor de lo invisible», in: MCU, Libro Blanco de la traducción editorial en España, Madrid: MEC, 29-36.

MARCo, José - Verdegal, Joan - HurTAdo, Amparo (1999), «La traducción literaria», in: Hurtado Albir, Amparo (dir.), Enseñar a traducir. Metodología en la formación de traductores e intérpretes, Madrid: Edelsa.

MCU (2010), Libro Blanco de la traducción editorial en España, Madrid: MEC. 
Merino, Mario (2005), «En esta tarea deben colaborar editores, libreros, críticos y buenos lectores», Delibros 185, 19-28.

Montero Domínguez, Xoán (ed.) (2010), Tradución para a dobraxe en Galicia, País Vasco e Cataluña. Experiencias investigadoras e profesionais, Vigo: Servizo de Publicacións da Universidade de Vigo.

MONTERO KüPPER, Silvia (2012), «Contextualización histórico-cultural y apuntes sobre el sector editorial gallego», in: Fernández RodrígueZ, Áurea Amparo - Galanes SAntos, Iolanda - LunA Alonso, Ana - Montero KüPPer, Silvia, Traducción de una Cultura Emergente: La Literatura Gallega Contemporánea en el Exterior, Bern: Peter Lang.

RABADÁN, Rosa (1991), Equivalencia y traducción: problemática de la equivalencia translémica inglés-español, León: Universidad de León.

RABADÁN, Rosa (2000), Traducción y censura inglés-español, 1939-1985: estudio preliminar, León: Universidad de León.

Vidal Claramonte, Ma Carmen África (1998), El futuro de la traducción: últimas teorías, nuevas aplicaciones, Valencia: Diputacion de València, Institució Alfons el Magnànim, D.L.

Vidal Claramonte, $\mathrm{M}^{\mathrm{a}}$ Carmen África (2005), En los límites de la traducción, Granada: Comares.

Vidal Claramonte, Ma Carmen África (2010), Traducción y asimetría, Frankfurt am Main: Peter Lang.

VV. AA. (2003), Informe sobre la situación del traductor de libros en España, Madrid: ACEtt (http://www.acett.org/, consulta 10-07-13).

Ana Luna Alonso

Facultad de Traducción e Interpretación

Campus Universitario Lagoas-Marcosende

Universidad de Vigo

36200 Vigo

España

aluna@uvigo.es 